\title{
REVIEW
}

\section{Ventilator-associated pneumonia in the ICU}

\author{
Atul Ashok Kalanuria', Wendy Zai²*, Marek Mirski \\ This article is one of ten reviews selected from the Annual Update in Intensive Care and Emergency Medicine 2014 and co-published as a series \\ in Critical Care. Other articles in the series can be found online at http://ccforum.com/series/annualupdate2014. Further information about the \\ Annual Update in Intensive Care and Emergency Medicine is available from http://www.springer.com/series/8901.
}

\section{Introduction}

Ventilator-associated pneumonia (VAP) is defined as pneumonia that occurs 48-72 hours or thereafter following endotracheal intubation, characterized by the presence of a new or progressive infiltrate, signs of systemic infection (fever, altered white blood cell count), changes in sputum characteristics, and detection of a causative agent [1]. VAP contributes to approximately half of all cases of hospital-acquired pneumonia [1], [2]. VAP is estimated to occur in 9-27\% of all mechanically ventilated patients, with the highest risk being early in the course of hospitalization [1], [3]. It is the second most common nosocomial infection in the intensive care unit (ICU) and the most common in mechanically ventilated patients [4], [5]. VAP rates range from 1.2 to 8.5 per 1,000 ventilator days and are reliant on the definition used for diagnosis [6]. Risk for VAP is greatest during the first 5 days of mechanical ventilation (3\%) with the mean duration between intubation and development of VAP being 3.3 days [1], [7]. This risk declines to $2 \% /$ day between days 5 to 10 of ventilation, and $1 \%$ /day thereafter [1], [8]. Earlier studies placed the attributable mortality for VAP at between $33-50 \%$, but this rate is variable and relies heavily on the underlying medical illness [1]. Over the years, the attributable risk of death has decreased and is more recently estimated at 9-13\% [9], [10], largely because of implementation of preventive strategies. Approximately $50 \%$ of all antibiotics administered in ICUs are for treatment of VAP [2], [4]. Early onset VAP is defined as pneumonia that occurs within 4 days and this is usually attributed to antibiotic sensitive pathogens whereas late onset VAP is more likely caused by multidrug resistant (MDR) bacteria and emerges after 4 days of intubation [1], [4]. Thus, VAP poses grave implications in endotracheally intubated adult patients in

*Correspondence: weziai@jhmi.edu

${ }^{2}$ Department of Anesthesiology/Critical Care Medicine, Johns Hopkins University School of Medicine, Baltimore, MD 21287, USA

Full list of author information is available at the end of the article
ICUs worldwide and leads to increased adverse outcomes and healthcare costs. Independent risk factors for development of VAP are male sex, admission for trauma and intermediate underlying disease severity, with odds ratios (OR) of 1.58, 1.75 and 1.47-1.70, respectively [7].

\section{Pathogenesis}

The complex interplay between the endotracheal tube, presence of risk factors, virulence of the invading bacteria and host immunity largely determine the development of VAP. The presence of an endotracheal tube is by far the most important risk factor, resulting in a violation of natural defense mechanisms (the cough reflex of glottis and larynx) against microaspiration around the cuff of the tube [4], [11]. Infectious bacteria obtain direct access to the lower respiratory tract via: (1) microaspiration, which can occur during intubation itself; (2) development of a biofilm laden with bacteria (typically Gram-negative bacteria and fungal species) within the endotracheal tube; (3) pooling and trickling of secretions around the cuff; and (4) impairment of mucociliary clearance of secretions with gravity dependence of mucus flow within the airways [11]-[13]. Pathogenic material can also collect in surrounding anatomic structures, such as the stomach, sinuses, nasopharynx and oropharynx, with replacement of normal flora by more virulent strains [11], [12], [14]. This bacterium-enriched material is also constantly thrust forward by the positive pressure exerted by the ventilator. Whereas reintubation following extubation increases VAP rates, the use of non-invasive positive pressure ventilation has been associated with significantly lower VAP rates [4]. Host factors such as the severity of underlying disease, previous surgery and antibiotic exposure have all been implicated as risk factors for development of VAP [1].

In addition, it has recently been noted that critically ill patients may have impaired phagocytosis and behave as functionally immunosuppressed even prior to emergence of nosocomial infection [4], [15], [16]. This effect is attributed to the detrimental actions of the anaphylatoxin, 
C5a, which impairs neutrophil phagocytic activity and impairs phagocytosis by neutrophils [15]. More recently, a combined dysfunction of T-cells, monocytes, and neutrophils has been noted to predict acquisition of nosocomial infection [16]. For example, elevation of regulatory T-cells (Tregs), monocyte deactivation (measured by monocyte HLA-DR expression) and neutrophil dysfunction (measured by CD88 expression), have cumulatively shown promise in predicting infection in the critically ill population, as compared to healthy controls [16].

\section{Microbiology}

The type of organism that causes VAP usually depends on the duration of mechanical ventilation. In general, early VAP is caused by pathogens that are sensitive to antibiotics, whereas late onset VAP is caused by multi-drug resistant and more difficult to treat bacteria. However, this is by no means a rule and merely a guide to initiate antibiotic therapy until further clinical information is available.

Typically, bacteria causing early-onset VAP include Streptococcus pneumoniae (as well as other streptococcus species), Hemophilus influenzae, methicillin-sensitive Staphylococcus aureus (MSSA), antibiotic-sensitive enteric Gram-negative bacilli, Escherichia coli, Klebsiella pneumonia, Enterobacter species, Proteus species and Serratia marcescens. Culprits of late VAP are typically MDR bacteria, such as methicillin-resistant S. aureus (MRSA), Acinetobacter, Pseudomonas aeruginosa, and extended-spectrum beta-lactamase producing bacteria (ESBL) [4]. The exact prevalence of MDR organisms is variable between institutions and also within institutions [1]. Patients with a history of hospital admission for $\geq 2$ days in the past 90 days, nursing home residents, patients receiving chemotherapy or antibiotics in the last 30 days and patients undergoing hemodialysis at outpatient centers are susceptible to drug resistant bacteria [1], [4]. Commonly found bacteria in the oropharynx can attain clinically significant numbers in the lower airways. These bacteria include Streptococcus viridans, Corynebacterium, coagulase-negative staphylococcus (CNS) and Neisseria species. Frequently, VAP is due to polymicrobial infection. VAP from fungal and viral causes has a very low incidence, especially in the immunocompetent host [1].

Pathogens causing VAP, their frequency (in parenthesis) and their possible mode of multi-drug resistance, if any, are listed below [1]-[3]:

1. Pseudomonas (24.4\%): Upregulation of efflux pumps, decreased expression of outer membrane porin channel, acquisition of plasmid-mediated metallobeta-lactamases.

2. S. aureus ( $20.4 \%$, of which $>50 \%$ MRSA): Production of a penicillin-binding protein (PBP) with reduced affinity for beta-lactam antibiotics. Encoded by the mecA gene.

3. Enterobacteriaceae $(14.1 \%$ - includes Klebsiella spp., E. coli, Proteus spp., Enterobacter spp., Serratia spp., Citrobacter spp.): Plasmid mediated production of ESBLs, plasmid-mediated AmpC-type enzyme.

4. Streptococcus species (12.1\%).

5. Hemophilus species (9.8\%).

6. Acinetobacter species (7.9\%): Production of metalloenzymes or carbapenemases.

7. Neisseria species (2.6\%).

8. Stenotrophomonas maltophilia (1.7\%).

9. Coagulase-negative staphylococcus (1.4\%).

10. Others (4.7 \% - includes Corynebacterium, Moraxella, Enterococcus, fungi).

\section{Diagnosis}

At the present time, there is no universally accepted, gold standard diagnostic criterion for VAP. Several clinical methods have been recommended but none have the needed sensitivity or specificity to accurately identify this disease [17]. Daily bedside evaluation in conjunction with chest radiography can only be suggestive of the presence or absence of VAP, but not define it [18]. Clinical diagnosis of VAP can still miss about a third of VAPs in the ICU compared to autopsy findings and can incorrectly diagnose more than half of patients, likely due to poor interobserver agreement between clinical criteria [8], [18], [19]. Postmortem studies comparing VAP diagnosis with clinical criteria showed $69 \%$ sensitivity and $75 \%$ specificity, in comparison to autopsy findings [20].

The American Thoracic Society (ATS) and the Infectious Diseases Society of America (IDSA) guidelines recommend obtaining lower respiratory tract samples for culture and microbiology [1]. Analysis of these samples can be quantitative or qualitative. This guideline also allows use of tracheal aspirates for their negative predictive value ( $94 \%$ for VAP). Johanson et al. described clinical criteria for diagnosis of VAP as follows [21]: The clinical pulmonary infection score (CPIS) takes into account clinical, physiological, microbiological and radiographic evidence to allow a numerical value to predict the presence or absence of VAP (Table 1) [18], [22]. Scores can range between zero and 12 with a score of $\geq 6$ showing good correlation with the presence of VAP [22]. Despite the clinical popularity of the CPIS, debate continues regarding its diagnostic validity. One metaanalysis of 13 studies evaluating the accuracy of CPIS in diagnosing VAP reported pooled estimates for sensitivity and specificity for CPIS as $65 \%$ (95\% CI 61-69 \%) and $64 \%$ (95\% CI 60-67\%), respectively [23]. Despite its apparent straightforward calculation, the inter-observer variability in CPIS calculation remains substantial, jeopardizing its routine use in clinical trials [24]. Of all 
Table 1 The clinical pulmonary infection score (CPIS)

\begin{tabular}{|c|c|c|}
\hline Assessed Parameter & Result & Score \\
\hline Temperature ( ${ }^{\circ} \mathrm{Celsius)}$ & $\begin{array}{l}36.5-38.4^{\circ} \mathrm{C} \\
38.5-38.9^{\circ} \mathrm{C} \\
\leq 36 \text { or } \geq 39^{\circ} \mathrm{C}\end{array}$ & $\begin{array}{l}0 \\
1 \\
2\end{array}$ \\
\hline Leukocytes in blood (cells/mm³) & $\begin{array}{l}4,000-11,000 / \mathrm{mm}^{3} \\
<4,000 \text { or }>11,000 / \mathrm{mm}^{3} \\
\geq 500 \text { Band cells }\end{array}$ & $\begin{array}{l}0 \\
1 \\
2\end{array}$ \\
\hline Tracheal secretions (subjective visual scale) & $\begin{array}{l}\text { None } \\
\text { Mild/non-purulent } \\
\text { Purulent }\end{array}$ & $\begin{array}{l}0 \\
1 \\
2\end{array}$ \\
\hline Radiographic findings (on chest radiography, excluding CHF and ARDS) & $\begin{array}{l}\text { No infiltrate } \\
\text { Diffuse/patchy infiltrate } \\
\text { Localized infiltrate }\end{array}$ & $\begin{array}{l}0 \\
1 \\
2\end{array}$ \\
\hline Culture results (endotracheal aspirate) & $\begin{array}{l}\text { No or mild growth } \\
\text { Moderate or florid growth } \\
\text { Moderate or florid growth AND pathogen consistent with Gram stain }\end{array}$ & $\begin{array}{l}0 \\
1 \\
2\end{array}$ \\
\hline Oxygenation status (defined by $\mathrm{PaO}_{2}, \mathrm{FiO}_{2}$ ) & $\begin{array}{l}>240 \text { or ARDS } \\
\leq 240 \text { and absence of ARDS }\end{array}$ & $\begin{array}{l}0 \\
2\end{array}$ \\
\hline
\end{tabular}

ARDS: acute respiratory distress syndrome; $\mathrm{CHF}$ : congestive heart failure

the criteria used to calculate the CPIS, only timedependent changes in the $\mathrm{PaO}_{2} / \mathrm{FiO}_{2}$ ratio early in VAP may provide some predictive power for VAP outcomes in clinical trials, namely clinical failure and mortality [25]. However, a trial by Singh and colleagues [26] demonstrated that the CPIS is an effective clinical tool for determining whether to stop or continue antibiotics for longer than 3 days. In that study, antibiotics were discontinued at day 3 for patients who had been randomized to receive ciprofloxacin instead of standard of care, if their CPIS remained $\leq 6$. Mortality and length of ICU stay did not differ despite a shorter duration $(\mathrm{p}=0.0001)$ and lower cost $(p=0.003)$ of antimicrobial therapy in the experimental as compared with the standard therapy arm, and the development of antimicrobial resistance was lower among patients whose antibiotics were discontinued compared to those who received standard of care.

1. New or progressive radiographic consolidation or infiltrate. In addition, at least 2 of the following:

2. Temperature $>38^{\circ} \mathrm{C}$

3. Leukocytosis (white blood cell count $\geq 12,000$ cells/ $\mathrm{mm}^{3}$ ) or leukopenia (white blood cell count $<4,000$ cells $/ \mathrm{mm}^{3}$ )

4. Presence of purulent secretions

Respiratory samples can be obtained using several techniques: The ATS/IDSA guidelines note that use of a bronchoscopic bacteriologic strategy has been shown to reduce 14-day mortality when compared with a clinical strategy (16.2 \% vs. $25.8 \%, \mathrm{p}=0.02)$ [1]. When samples are obtained by BAL techniques (BAL, mini-BAL or PSB), the diagnostic threshold is $10^{3}$ colony forming units $(\mathrm{cfu}) / \mathrm{ml}$ for protected specimen brushing and $10^{4} \mathrm{cfu} / \mathrm{ml}$ for BAL. In one multicenter study, BAL- and PSB-based diagnosis was associated with significantly more antibiotic-free days $(11.5 \pm 9.0$ vs. $7.5 \pm 7.6, \mathrm{p}<0.001)$ compared to guideline-based clinical diagnosis alone [27]. This study also demonstrated short-term mortality benefit in the BAL/PSB group. More recent evidence from the Canadian Clinical Trials study of 740 suspected VAP patients randomized to BAL or tracheal suctioning suggests that (excluding patients known to be colonized/ infected with pseudomonas species or MRSA) similar clinical outcomes and overall use of antibiotics is observed when either BAL with quantitative culture or endotracheal aspiration with non-quantitative culture is used for diagnosis [28]. This finding was confirmed by a Cochrane meta-analysis of 1,367 patients which again found no difference in mortality in the invasive vs. noninvasive groups ( $26.6 \%$ and $24.7 \%$, respectively), in quantitative versus qualitative cultures (relative risk 1.53, $95 \%$ CI 0.54-4.39) or in antibiotic use [29].

1. Endotracheal aspirate: Easiest to obtain, does not require provider involvement.

2. Bronchoalveolar lavage (BAL): Requires bronchoscopic guidance.

3. Mini-bronchoalveolar lavage (mini-BAL): Performed 'blind', i. e., without bronchoscopic guidance.

4. Protected specimen brush (PSB): Utilizes a brush at the tip of the catheter which is rubbed against the bronchial wall.

Once specimens are obtained, the sample is sent for Gram stain, culture and sensitivity. The Gram stain can provide crucial initial clues to the type of organism(s) and whether or not the material is purulent (defined as $\geq 25$ neutrophils and $\leq 10$ squamous epithelial cells per low power field) [1],[12]. Culture results can be reported as semi-quantitative and/or quantitative values. Semiquantitative values obtained by endotracheal sampling are considered positive when the agar growth is moderate 
$(+++)$ or heavy $(++++)$, while quantitative positivity is defined as $\geq 10^{5} \mathrm{cfu} / \mathrm{ml}$. Exact speciation of pathogen bacteria and their sensitivity to antibiotics can take a few days, but provides invaluable information.

Mechanically ventilated patients in the ICU receive frequent chest X-rays and presence of infiltrate(s) and/or consolidation is considered part of diagnostic criteria and is widely used. However, there are several clinical conditions that have radiographic appearances similar to VAP. These conditions are commonly encountered in mechanically ventilated patients and include aspiration and chemical pneumonitis, atelectasis, congestive heart failure, acute respiratory distress syndrome (ARDS), pleural effusion and intra-alveolar hemorrhage to name a few. Hence, reliance on chest radiography for the diagnosis of VAP is not advisable. There is poor correlation between radiographic signs (alveolar infiltrates, air bronchograms) and histopathological diagnosis of pneumonia [12]. The sensitivity and specificity of presence of infiltrates on chest X-ray is also not encouraging [12]. On the flip-side, the negative predictive value of infiltrates may have clinical utility. In a meta-analysis by Klompas, the presence or absence of fever, elevated white blood cell count, or purulent secretions did not substantively predict the probability of infection; however, the absence of a new infiltrate on a plain radiograph lowered the likelihood of VAP [18].

VAP must be distinguished from tracheo-bronchitis. Clinical features of these diseases can overlap, but only VAP will demonstrate the presence of hypoxia and the presence of infiltrate/consolidation on chest radiography [12].

Recently, the Centers for Disease Control and Prevention (CDC) rolled out new surveillance criteria for possible or probable VAP [17]. The goals were to capture other common complications of ventilator care, to improve objectivity of surveillance to allow comparability across centers for public reporting, and to minimize gaming [30]. Per these new criteria, a period of at least 2 days of stable or decreasing ventilator settings (daily minimum positive end-expiratory pressure [PEEP] or fraction of inspired oxygen $\left[\mathrm{FiO}_{2}\right]$ ) followed by consistently higher settings for at least 2 additional calendar days is required before a patient can be said to have a ventilator-associated condition (VAC). Most VACs are attributable to pneumonia, pulmonary edema, atelectasis, or ARDS, conditions which all have well researched prevention and management strategies [31]. Signs of infection/inflammation (abnormal temperature or whitecell count and administration of one or more new antibiotics for at least 4 days) classify the patient as an "infection-related ventilator-associated complication," or IVAC. Presence of purulent secretions (according to quantitative Gram staining criteria) and pathogenic culture data will label the patient as possible or probable VAP. Patients with an IVAC and purulent secretions alone or pathogenic cultures alone have "possible pneumonia"; those with both purulent secretions and positive quantitative or semiquantitative cultures have "probable pneumonia". Probable pneumonia is also defined by suggestive histopathological features, positive pleuralfluid cultures, or diagnostic tests for legionella and selected viruses. Chest radiograph findings have been excluded in the new criteria because of their subjectivity without increased accuracy. This is not intended to reduce the role of radiography in clinical care. At the present time, the new CDC algorithm is for surveillance purposes only.

In the United States, VAP has been proposed as an indicator of quality of care in public reporting, and its prevention is a national patient safety goal. The threat of non-reimbursement and financial penalties for this diagnosis has put pressure on hospitals to minimize VAP rates [13]. This has resulted in potential artifacts in surveillance with more than $50 \%$ of non-teaching medical ICUs in the United States reporting VAP rates close to zero [30], [32]. These rates are an order of magnitude lower than those in European centers, which utilize similar preventive and treatment strategies suggesting that reductions in VAP rates may not reflect improvements in prevention so much as subjective surveillance biases. It is anticipated that the new CDC surveillance paradigm for ventilator-associated events will help achieve a more realistic VAP rate.

\section{Treatment}

Selecting the appropriate antibiotic depends on the duration of mechanical ventilation. Late onset VAP ( $>4$ days) requires broad spectrum antibiotics whereas early onset ( $\leq 4$ days) can be treated with limited spectrum antibiotics [1]. An updated local antibiogram for each hospital and each ICU based on local bacteriological patterns and susceptibilities is essential to guide optimally dosed initial empiric therapy [1]. With any empiric antibiotic regimen, de-escalation is the key to reduce emergence of resistance [33]. Delays in initiation of antibiotic treatment may add to the excess mortality risk with VAP [1]. Tables 2 and 3 highlight the recommended treatment regimens for VAP.

Owing to the high rate of resistance to monotherapy observed with $P$. aeruginosa, combination therapy is always recommended. Acinetobacter species respond best to carbapenems (also active against ESBL positive Enterobacteriaceae), colistin, polymyxin B and ampicillin/sulbactam [36], [37]. Although MDR organisms are usually associated with late-onset VAP, recent evidence suggests that they are increasingly associated with earlyonset VAP as well [37], [38]. The role of inhaled 
Table 2 Comparison of recommended initial empiric therapy for ventilator-associated pneumonia (VAP) according to time of onset [1], [34], [41]

\begin{tabular}{|c|c|}
\hline Early-onset VAP & Late-onset VAP \\
\hline Second or third generation cephalosporin: e. g., ceftriaxone: $2 \mathrm{~g}$ daily; & Cephalosporin \\
\hline cefuroxime: 1.5 g every 8 hours; & e. g., cefepime: $1-2$ g every 8 hours; \\
\hline cefotaxime: $2 \mathrm{~g}$ every 8 hours & ceftazidime $2 \mathrm{~g}$ every 8 hours \\
\hline OR & $\mathrm{OR}$ \\
\hline Fluoroquinolones & Carbepenem \\
\hline e. g., levofloxacin: 750 mg daily; & e. g., imipenem + cilastin: $500 \mathrm{mg}$ every 6 hours or $1 \mathrm{~g}$ every 8 hours; \\
\hline moxifloxacin: 400 mg daily & meropenem: $1 \mathrm{~g}$ every 8 hours \\
\hline OR & OR \\
\hline \multirow{2}{*}{$\begin{array}{l}\text { Aminopenicillin + beta-lactamase inhibitor e. g., ampicillin + sulbactam: } 3 \mathrm{~g} \\
\text { every } 8 \text { hours }\end{array}$} & Beta-lactam/beta-lactamase inhibitor \\
\hline & e. g., piperacillin + tazobactam: $4.5 \mathrm{~g}$ every 6 hours \\
\hline OR & PLUS \\
\hline \multirow{13}{*}{$1 \mathrm{~g}$ daily } & Aminoglycoside \\
\hline & e. g., amikacin: 20 mg/kg/day; \\
\hline & gentamicin: 7 mg/kg/day; \\
\hline & tobramycin: 7 mg/kg/day \\
\hline & OR \\
\hline & Antipseudomonal fluoroquinolone \\
\hline & e. g., ciprofloxacin 400 mg every 8 hours; \\
\hline & levofloxacin 750 mg daily \\
\hline & PLUS \\
\hline & Coverage for MRSA \\
\hline & e. g., vancomycin: $15 \mathrm{mg} / \mathrm{kg}$ every 12 hours \\
\hline & OR \\
\hline & linezolid: 600 mg every 12 hours \\
\hline
\end{tabular}

Optimal dosage includes adjusting for hepatic and renal failure. Trough levels for vancomycin (15-20 mcg/ml), amikacin ( $<5 \mathrm{mcg} / \mathrm{ml})$, gentamicin $(<1 \mathrm{mcg} / \mathrm{ml})$ and tobramycin $(<1 \mathrm{mcg} / \mathrm{ml})$ should be measured frequently to avoid untoward systemic side effects. All recommended doses are for intravenous infusion. Usual duration of therapy is 8 days unless treatment is for multidrug resistant organisms, in which case treatment will be for 14 days.

antibiotics in the setting of failure of systemic antibiotics is unclear [1]. The usual duration of treatment for earlyonset VAP is 8 days and longer in the case of late-onset VAP or if MDR organisms are suspected or identified [39]-[41].

Despite therapy, if no response is observed, it may be prudent to reconsider the diagnosis, reassess the organism being treated or search for other reasons for signs and symptoms. Because of the challenges associated with diagnosing VAP, especially early in the course, the IDSA/ATS guidelines highlight the importance of reassessing patients at $48-72$ hours once pertinent data are available to determine whether the patient should continue antibiotic therapy for VAP or whether an alternative diagnosis should be pursued. In one study, Swoboda et al. [42] found that half of the empiric antibiotic use for VAP in two surgical ICUs was prescribed for patients without pneumonia.

\section{Prevention}

There are multiple recommended measures for prevention of VAP. These measures are summarized in Table 4 [43]-[46]. Institutions or ICUs may observe a reduction in VAP rates by utilizing a 'VAP-bundle' approach [44], [47] using elements depicted in Table 4. The 5-element Institute of Healthcare Improvement (IHI) VAP bundle [47] includes: Head of bed elevation, oral care with chlorhexidine, stress ulcer prophylaxis, deep venous thrombosis prophylaxis, and daily sedation assessment and spontaneous breathing trials. Each of these elements has been shown to reduce the incidence of VAP although the quality of evidence supporting the effectiveness and importance of each intervention has been questioned. Even studies using VAP bundles have been criticized as failing to demonstrate clinical and cost effectiveness [48]. A before-after study which systematically implemented a VAP prevention bundle using IHI methodology showed a 
Table 3 Recommended therapy for suspected or confirmed multidrug resistant organisms and fungal VAP [1], [34], [35], [41]

\begin{tabular}{|c|c|}
\hline Pathogen & Treatment \\
\hline Methicillin-resistant Staphylococcus aureus (MRSA) & See Table 2 \\
\hline Pseudomonas aeruginosa & Double coverage recommended. See Table 2 \\
\hline \multirow[t]{9}{*}{ Acinetobacter species } & Carbapenem \\
\hline & e. g., imipenem + cilastin; 1 g every 8 hours; \\
\hline & meropenem $1 \mathrm{~g}$ every 8 hours \\
\hline & OR \\
\hline & Beta-Lactam/beta-lactamase inhibitor \\
\hline & e. g., ampicillin + sulbactam: 3 g every 8 \\
\hline & hours \\
\hline & OR \\
\hline & Tigecycline: $100 \mathrm{mg}$ loading dose, then $50 \mathrm{mg}$ every 12 hours \\
\hline \multirow[t]{3}{*}{ Extended-spectrum beta-lactamase (ESBL) positive enterobacteriaceae } & Carbepenem \\
\hline & e. g., imipenem + cilastin: 1 g every 8 hours; \\
\hline & meropenem: $1 \mathrm{~g}$ every 8 hours \\
\hline \multirow[t]{3}{*}{ Fungi } & Fluconazole: 800 mg every 12 hours; \\
\hline & caspofungin: 70 mg loading dose, then 50 mg daily; \\
\hline & voriconazole (for aspergillus species): 4 mg/kg every 12 hours \\
\hline \multirow[t]{3}{*}{ Legionella } & Macrolides (e. g., azithromycin) \\
\hline & OR \\
\hline & Fluoroquinolones (e. g., levofloxacin) \\
\hline
\end{tabular}

Table 4 Suggested measures for prevention of ventilator-associated pneumonia (VAP) [41], [42], [49]

ICU focused measures
Alcohol-based hand washing policy
Early discontinuation of invasive devices
Reduce reintubation rates
Use of oropharyngeal vs. nasopharyngeal feeding tubes

Semi-recumbent patient positioning $\left(30-45^{\circ}\right)$

Endotracheal tube cuff pressure $\sim 20 \mathrm{~cm} \mathrm{H}_{2} \mathrm{O}$

Early tracheostomy

Small bowel feeding instead of gastric feeding

Prophylactic probiotics

\section{Institution focused measures}

Surveillance program for pathogen profiling and creation of "antibiogram"

Frequent educational programs to reduce unnecessary antibiotic prescription

Propagate use of non-invasive positive pressure ventilation (NIPPV)

Endotracheal tubes (ETTS) with potential benefit:

Polyurethane-cuffed ETT

Silver/antibiotic coated ETT

Aspiration of subglottic secretions (HI-LO ETT)

Maintain policy for oral decontamination

Selective digestive decontamination (SDD)

Early weaning and extubation

Daily sedation holds

Preference on using heat-moisture exchangers over heater humidifiers

Mechanical removal of the biofilm (e. g., the mucus shaver) significant reduction in VAP rates, antibiotic use and MRSA acquisition [43]. There was no reduction, however, in duration of mechanical ventilation or ICU admission. The IHI emphasizes the need for high (95\%) overall compliance rates with VAP bundles although this particular study reported overall bundle compliance rates of $70 \%$.
Issues with completeness of documentation may underestimate compliance, which remains an important feature of VAP bundle prevention strategies. Another important contribution towards VAP prevention and shortening periods of antibiotic exposure was a recent prospective study ( $\mathrm{n}=129)$, which concluded that a single-dose of 
antibiotics within $4 \mathrm{~h}$ of intubation may be effective in preventing early onset VAP in a cohort of comatose patients [49]. A randomized clinical trial is needed to address this question.

\section{Conclusion}

VAP occurs frequently and is associated with significant morbidity in critically ill patients. The primary obstacle in diagnosing VAP is the absence of gold standard criteria and, therefore, VAP continues to be an inconspicuous clinical syndrome. There is enough evidence to indicate that VAP is preventable and that hospitals can decrease VAP rates, a factor that the new CDC VAP definitions are poised to demonstrate more objectively. The diagnostic challenge of VAP has multiple implications for therapy. Although a CPIS score $>6$ may correlate with VAP, the sensitivity, specificity and inter-rater agreement of this criterion alone are not encouraging. Microbiological data should be used for tailoring antibiotic therapy and not be restricted only to diagnosis. The pitfall in using empiric antibiotics for suspicion of VAP is the potential for antibiotic overuse, emergence of resistance, unnecessary adverse effects and potential toxicity. The major goals of VAP management are early, appropriate antibiotics in adequate doses followed by de-escalation based on microbiological culture results and the clinical response of the patient. Antimicrobial stewardship programs involving pharmacists, physicians and other healthcare providers optimize antibiotic selection, dose, and duration to increase efficacy in targeting causative pathogens and allow the best clinical outcome.

\section{List of abbreviations used}

ARDS: acute respiratory distress syndrome; ATS: American Thoracic Society; BAL: Bronchoalveolar lavage; CDC: Centers for Disease Control and Prevention; CHF: congestive heart failure; $\mathrm{Cl}$ : confidence interval; CNSL coagulase-negative staphylococcus; CPIS: clinical pulmonary infection score; ESBL: extendedspectrum beta-lactamase producing bacteria ( $\mathrm{ESBL}$ ); $\mathrm{FiO}_{2}$ : fraction of inspired oxygen; ICU: intensive care unit; IVAC: infection-related ventilator-associated complication; IDSA: Infectious Diseases Society of America; MDR: multi drug resistant; Mini-BAL - mini-bronchoalvelolar lavage; MRSA: methicillin-resistant Staphylococcus aureus; MSSA: methicillin-senstive Staphylococcus aureus; OR: odds ratios; PBP: penicillin-binding protein; PEEP: positive end-expiratory pressure; PSB: protected specimen brush; Tregs: regulatory T-cells; VAP: ventilator-associated pneumonia.

\section{Competing interests}

The authors declare that they have no competing interests.

\section{Declarations}

Publication costs for this article were funded by the authors' institutions.

\section{Author details}

'Department of Neurology, University of Maryland School of Medicine, Baltimore, MD 21201, USA. ${ }^{2}$ Department of Anesthesiology/Critical Care Medicine, Johns Hopkins University School of Medicine, Baltimore, MD 21287, USA.

Published: 18 March 2014
References

1. American Thoracic Society, Infectious Diseases Society of America: Guidelines for the management of adults with hospital-acquired, ventilator-associated, and healthcare-associated pneumonia. Am J Respir Crit Care Med 2005, 171:388-416.

2. Vincent JL, Bihari DJ, Suter PM, Bruining HA, White J, Nicolas-Chanoin MH, Wolff M, Spencer RC, Hemmer M: The prevalence of nosocomial infection in intensive care units in Europe. JAMA 1995, 274:639-644

3. Chastre J, Fagon JY: State of the art: ventilator-associated pneumonia. Am J Respir Crit Care Med 2002, 165:867-903.

4. Hunter JD: Ventilator associated pneumonia. BMJ 2012, 344(e3325):e3325

5. Afshari A, Pagani L, Harbarth S: Year in review 2011: Critical care - infection. Crit Care 2012, 16:242-247.

6. Skrupky LP, McConnell K, Dallas J, Kollef MH: A comparison of ventilatorassociated pneumonia rates as identified according to the National Healthcare Safety Network and American College of Chest Physicians Criteria. Crit Care Med 2012, 40:281-284.

7. Rello J, Ollendorf D, Oster G, Vera-Llonch M, Bellm L, Redman R, Kollef MH, VAP Outcomes Scientific Advisory Group: Epidemiology and outcomes of ventilator-associated pneumonia in a large US database. Chest 2002, 122:2115-2121.

8. Cook DJ, Walter SD, Cook RJ, Griffith LE, Guyatt GH, Leasa D, Jaeschke RZ, Brun-Buisson C: Incidence of and risk factors for ventilator-associated pneumonia in critically ill patients. Ann Int Med 1998, 129:433-440.

9. Melsen WG, Rovers MM, Koeman M, Bonten MJM: Estimating the attributable mortality of ventilator-associated pneumonia from randomized prevention studies. Crit Care Med 2011, 39:2736-2742.

10. Melsen WG, Rovers MM, Groenwold RH, Bergmans DC, Camus C, Bauer TT, Hanisch EW, Klarin B, Koeman M, Krueger WA, Lacherade JC, Lorente L, Memish ZA, Morrow LE, Nardi G, van Nieuwenhoven CA, O'Keefe GE, Nakos G, Scannapieco FA, Sequin P, Staudinger T, Topeli A, Ferrer M, Bonten MJ: Attributable mortality of ventilator-associated pneumonia: a metaanalysis of individual patient data from randomised prevention studies Lancet Infect Dis 2013, 13:665-671.

11. Zolfaghari PS, Wyncoll DL: The tracheal tube: gateway to ventilatorassociated pneumonia. Crit Care 2011, 15:310-317.

12. Grgurich PE, Hudcova J, Lei Y, Sarwar A, Craven DE: Diagnosis of ventilatorassociated pneumonia: controversies and working toward a gold standard. Curr Opin Infect Dis 2013, 26:140-150.

13. Mietto C, Pinciroli R, Patel N, Berra L: Ventilator associated pneumonia: evolving definitions and preventive strategies. Respir Care 2013, 58:990-1007.

14. Rocha LA, Marques Ribas R, da Costa Darini AL, Gontijo Filho PP: Relationship between nasal colonization and ventilator-associated pneumonia and the role of the environment in transmission of Staphylococcus aureus in intensive care units. Am J Infect Control 2013, 41:1236-1240.

15. Morris AC, Brittan M, Wilkinson TS, McAuley DF, Antonelli J, McCulloch C, Barr LC, McDonald NA, Dhaliwal K, Jones RO, Mackellar A, Haslett C, Hay AW, Swann DG, Anderson N, Laurenson IF, Davidson DJ, Rossi AG, Walsh TS, Simpson AJ: C5a-mediated neutrophil dysfunction is RhoA-dependent and predicts infection in critically ill patients. Blood 2011, 117:5178-5188.

16. Conway Morris A, Anderson N, Brittan M, Wilkinson TS, McAuley DF, Antonelli J, McCulloch C, Barr LC, Dhaliwal K, Jones RO, Haslett C, Hay AW, Swann DG, Laurenson IF, Davidson DJ, Rossi AG, Walsh TS, Simpson AJ: Combined dysfunctions of immune cells predict nosocomial infection in critically ill patients. Br J Anaesth 2013, 3:1-10.

17. National Healthcare Safety Network (NHSN) July 2013 CDC/NHSN Protocol Clarifications 2013, Available at: http://www.cdc.gov/nhsn/PDFs/ pscManual/10-VAE_FINAL.pdf Accessed Oct 2013

18. Klompas M: Clinician's Corner: Does this patient have ventilator-associated pneumonia? JAMA 2013, 297:1583-1593.

19. Petersen IS, Aru A, Skødt V, Behrendt N, Bols B, Kiss K, Simonsen K: Evaluation of pneumonia diagnosis in intensive care patients. Scand J Infect Dis 1999, 31:299-303

20. Fàbregas N, Ewig S, Torres A, Al-Abiary M, Ramirez J, de La Bellacasa JP, Bauer $\mathrm{T}$, Cabello $\mathrm{H}$ : Clinical diagnosis of ventilator associated pneumonia revisited: comparative validation using immediate post-mortem lung biopsies. Thorax 1999, 54:867-873

21. Johanson WG, Pierce AK, Sanford JP, Thomas GD: Nosocomial respiratory infections with gram-negative bacilli. The significance of colonization of the respiratory tract. Ann Int Med 1972, 77:701-706. 
22. Pugin J, Auckenthaler R, Mili N, Janssens JP, Lew PD, Suter PM: Diagnosis of ventilator-associated pneumonia by bacteriologic analysis of bronchoscopic and nonbronchoscopic "blind" bronchoalveolar lavage fluid. Am Rev Respir Dis 1991, 143:1121-1129.

23. Shan J, Chen HL, Zhu JH: Diagnostic accuracy of clinical pulmonary infection score for ventilator-associated pneumonia: a meta-analysis. Respir Care 2011, 56:1087-1094.

24. Zilberberg MD, Shorr AF: Ventilator-associated pneumonia: the clinical pulmonary infection score as a surrogate for diagnostics and outcome. Clin Infect Dis 2010, 1:S131-S135.

25. Shorr AF, Cook D, Jiang X, Muscedere J, Heyland D: Correlates of clinical failure in ventilator-associated pneumonia: insights from a large, randomized trial. J Crit Care 2008, 23:64-73.

26. Singh N, Rogers P, Atwood CW, Wagener MM, Yu VL: Short-course empiric antibiotic therapy for patients with pulmonary infiltrates in the intensive care unit. A proposed solution for indiscriminate antibiotic prescription. Am J Respir Crit Care Med 2000, 162:505-511.

27. Fagon JY, Chastre J, Wolff M, Gervais C, Parer-Aubas S, Stéphan F, Similowski T, Mercat A, Diehl JL, Sollet JP, Tenaillon A: Invasive and noninvasive strategies for management of suspected ventilator-associated pneumonia. A randomized trial. Ann Intern Med 2000, 132:621-630.

28. Canadian Critical Care Trials Group: A randomized trial of diagnostic techniques for ventilator-associated pneumonia. N Eng/ J Med 2013, 355:2619-2630.

29. Berton DC, Kalil AC, Cavalcanti M, Teixeira PJ (2012) Quantitative versus qualitative cultures of respiratory secretions for clinical outcomes in patients with ventilator-associated pneumonia Chocrane Database Syst Rev CD006482

30. Klompas M: Complications of mechanical ventilation - the CDC's new surveillance paradigm. N Engl J Med 2013, 368:1472-1475.

31. Hayashi Y, Morisawa K, Klompas M, Jones M, Bandeshe H, Boots R, Lipman J. Paterson DL: Toward improved surveillance: the impact of ventilatorassociated complications on length of stay and antibiotic use in patients in intensive care units. Clin Infect Dis 2013, 56:471-477.

32. Dudeck MA, Horan TC, Peterson KD, Allen-Bridson K, Morrell G, Pollock DA Edwards JR:National Healthcare Safety Network (NHSN) Report, data summary for 2010, device-associated module. Am J Infect Control 2011, 39:798-816.

33. Masterton RG: Antibiotic de-escalation. Crit Care Clin 2011, 27:149-162.

34. Torres A, Ewig S, Lode H, Carlet J: Defining, treating and preventing hospital acquired pneumonia: European perspective. Intensive Care Med 2009, 35:9-29.

35. Walkey AJ, O'Donnell MR, Wiener RS: Linezolid vs glycopeptide antibiotics for the treatment of suspected methicillin-resistant Staphylococcus aureus nosocomial pneumonia: a meta-analysis of randomized controlled trials. Chest 2011, 139:1148-1155.

36. Munoz-Price LS, Weinstein RA: Acinetobacter Infection. N Engl J Med 2008, 358:1271-1281.

37. Martin-Loeches I, Deja M, Koulenti D, Dimopoulos G, Marsh B, Torres A, Niderman MS, Rello J, EU-VAP Study Investigators: Potentially resistant microorganisms in intubated patients with hospital-acquired pneumonia: the interaction of ecology, shock and risk factors. Intensive Care Med 2013, 39:672-681.
38. Pasquale TR, Jabrocki B, Salstrom SJ, Wiemken TL, Peyrani P, Hague NZ, Scerpella EG, Ford KD, Zervos MJ, Ramirez JA, File TM Jr, IMPACT-HAP Study Group: Emergence of methicillin-resistant Staphylococcus aureus USA300 genotype as a major cause of late-onset nosocomial pneumonia in intensive care patients in the USA. Int J Infect Dis 2013, 17:e398-e403.

39. Capellier G, Mockly H, Charpentier C, Annane D, Blasco G, Desmettre T, Roch A, Faisy C, Cousson J, Limat S, Mercier M, Papazian L: Early-onset ventilatorassociated pneumonia in adults randomized clinical trial: comparison of 8 versus 15 days of antibiotic treatment. PloS one 2012, 7:e41290.

40. Chastre J, Wolff M, Fagon J-Y, Chevret S, Thomas F, Wermert D, Clementi E, Gonzalez J, Jusserand D, Asfar P, Perrin D, Fieux F, Aubas S, PneumA Trial Group: Comparison of 8 vs 15 days of antibiotic therapy for ventilatorassociated pneumonia in adults: a randomized trial. JAMA 2003, 290:2588-2598.

41. Dimopoulos G, Poulakou G, Pneumatikos IA, Armaganidis A, Kollef MH, Matthaiou DK: Short- versus long-duration antibiotic regimens for ventilator-associated pneumonia: a systematic review and meta-analysis. Chest 2013, 144:1759-1767.

42. Swoboda SM, Dixon T, Lipsett PA: Can the clinical pulmonary infection score impact ICU antibiotic days? Surg Infect (Larchmt) 2006, 7:331-339.

43. Morris AC, Hay AW, Swann DG, Everingham K, McCulloch C, McNulty J, Brooks O, Laurenson IF, Cook B, Walsh TS: Reducing ventilator-associated pneumonia in intensive care: impact of implementing a care bundle. Crit Care Med 2011, 39:2218-2224.

44. Alhazzani W, Almasoud A, Jaeschke R, Lo BW, Sindi A, Altayyar S, FoxRobichaud A: Small bowel feeding and risk of pneumonia in adult critically ill patients: a systematic review and meta-analysis of randomized trials. Crit Care 2013, 17:R127.

45. Muscedere J, Rewa O, McKechnie K, Jiang X, Laporta D, Heyland DK: Subglottic secretion drainage for the prevention of ventilator-associated pneumonia: a systematic review and meta-analysis. Crit Care Med 2011, 39:1985-1991

46. Morrow LE, Kollef MH: Recognition and prevention of nosocomial pneumonia in the intensive care unit and infection control in mechanical ventilation. Crit Care Med 2010, 38:S352-S362.

47. Youngquist P, Carroll M, Farber M, Macy D, Madrid P, Ronning J, Susag A: Implementing a ventilator bundle in a community hospital. Jt Comm Qual Patient Saf 2007, 33:219-225.

48. Zilberberg MD, Shorr AF, Kollef MH: Implementing quality improvements in the intensive care unit: Ventilator bundle as an example. Crit Care Med 2009, 37:305-309

49. Vallés J, Peredo R, Burqueño MJ, Rodrigues de Freitas AP, Millán S, Espasa M, Martín-Loeches I, Ferrer R, Suarez D, Artigas A: Efficacy of single-dose antibiotic against early-onset pneumonia in comatose patients who are ventilated. Chest 2013, 143:1219-1225.

doi:10.1186/cc13775

Cite this article as: Kalanuria AA, et al.: Ventilator-associated pneumonia in the ICU. Critical Care 2014, 18:208 